\title{
Mediterranean swordfish (Xiphias gladius Linnaeus, 1758) population structure revealed by microsatellite DNA: genetic diversity masked by population mixing in shared areas
}

\author{
Tommaso Righi ${ }^{1}$, Andera Splendiani ${ }^{1}$, Tatiana Fioravanti ${ }^{1}$, Andrea Petetta ${ }^{1}$, Michela Candelma ${ }^{1}$, Giorgia \\ Gioacchini $^{1}{ }^{\text {, Kyle Gillespie }}{ }^{2}$, Alex Hanke ${ }^{2}$, Oliana Carnevali $^{1}$, Vincenzo Caputo Barucchi $^{\text {Corresp. } 1}$ \\ 1 Dipartimento di Scienze della Vita e dell'Ambiente, Università Politecnica delle Marche, Ancona, Italy \\ 2 \\ 2 Fisheries and Oceans Canada, St. Andrews Biological Station, Ottawa, Canada \\ Corresponding Author: Vincenzo Caputo Barucchi \\ Email address: v.caputo@univpm.it
}

Background. The Mediterranean swordfish stock is overfished and considered not correctly managed. Elucidating the patterns of the Mediterranean swordfish population structure constitutes an essential prerequisite for effective management of this fishery resource. To date, few studies have investigated intra-Mediterranean swordfish population structure, and their conclusions are controversial.

Methods. A panel of 20 microsatellites DNA was used to investigate fine-scale population structuring of swordfish from six main fishing areas of the Mediterranean Sea.

Results. This study provides evidence to reject the hypothesis of a single swordfish population within the Mediterranean Sea. DAPC analysis revealed the presence of three genetic clusters and a high level of admixture within the Mediterranean Sea. Genetic structure was supported by significant $\mathrm{F}_{\mathrm{ST}}$ values while mixing was endorsed by the heterozygosity deficit observed in sampling localities indicative of a possible Wahlund effect, by sampling admixture individuals. Overall, our tests reject the hypothesis of a single swordfish population within the Mediterranean Sea. Homing towards the Mediterranean breeding areas may have generated a weak degree of genetic differentiation between populations even at the intrabasin scale. 


\section{Mediterranean swordfish (Xiphias gladius Linnaeus,} 2 1758) population structure revealed by microsatellite 3 DNA: genetic diversity masked by population mixing 4 in shared areas.

Tommaso Righi ${ }^{1}$, Andrea Splendiani ${ }^{1}$, Tatiana Fioravanti ${ }^{1}$, Andrea Petetta ${ }^{1}$, Michela Candelma ${ }^{1}$,

7 Giorgia Gioacchini ${ }^{1}$, Kyle Gillespie ${ }^{2}$, Alex Hanke ${ }^{2}$, Oliana Carnevali ${ }^{1}$, Vincenzo Caputo

8 Barucchi $^{1}$

9

${ }^{1}$ Dipartimento di Scienze della Vita e dell'Ambiente, Università Politecnica delle Marche,

11 Ancona, Ancona, Italy

$12{ }^{2}$ Fisheries and Oceans Canada, St. Andrews Biological Station, St. Andrews, New Brunswick, 13 Canada

14 Corresponding Author:

15 Vincenzo Caputo Barucchi ${ }^{1}$

Dipartimento di Scienze della Vita e dell'Ambiente - Università Politecnica delle Marche Via Brecce Bianche, 60131, Ancona, Italy Email address: v.caputo@univpm.it

\section{Abstract}

Background. The Mediterranean swordfish stock is overfished and considered not correctly managed. Elucidating the patterns of the Mediterranean swordfish population structure constitutes an essential prerequisite for effective management of this fishery resource. To date, few studies have investigated intra-Mediterranean swordfish population structure, and their conclusions are controversial.

Methods. A panel of 20 microsatellites DNA was used to investigate fine-scale population structuring of swordfish from six main fishing areas of the Mediterranean Sea.

Results. This study provides evidence to reject the hypothesis of a single swordfish population within the Mediterranean Sea. DAPC analysis revealed the presence of three genetic clusters and a high level of admixture within the Mediterranean Sea. Genetic structure was supported by significant $\mathrm{F}_{\mathrm{ST}}$ values while mixing was endorsed by the heterozygosity deficit observed in sampling localities indicative of a possible Wahlund effect, by sampling admixture individuals. Overall, our tests reject the hypothesis of a single swordfish population within the Mediterranean Sea. Homing towards the Mediterranean breeding areas may have generated a weak degree of genetic differentiation between populations even at the intra-basin scale.

\section{Introduction}


39 Sustainable harvesting of fish stocks is one of the primary objectives of fishery management 40 (Cochrane, 2002). Fish species frequently form different populations, which are genetically 41 structured through behavioural and geographical distributional differences (Reiss et al., 2009).

42 Consequently, the identification of population structure is an essential prerequisite for effective 43 and sustainable management of the fishery resources (Reiss et al., 2009). Delineation of spatial 44 management areas ignoring the spatial distribution and the relationships between fish 45 populations may result in depletion or extinction of the most vulnerable or local subpopulations 46 and loss of genetic diversity that reduces the ability for the species to evolve and adapt to 47 environmental changes. However, a frequent mismatch between ecological and biological 48 processes and management actions in the last decade has led to the decline of many fish stocks 49 (Reiss et al., 2009).

50 This is particularly true for marine pelagic fish species where the identification of population 51 structure is hampered by the low level of intraspecific heterogeneity (Ward, Woodwark \& 52 Skibinski, 1994) as a result of the absence of geographical barriers, long larval periods and their 53 widespread dispersal as well as highly migratory adults that facilitate high levels of gene flow. However, demographic history of the ancestral population combined with current ecological biogeographic factors, such as dispersal potential, spawning behaviour and population size, have led to population differentiation, as revealed by several genetic studies for different fish species (Zardoya et al., 2004; Martínez et al., 2006; Ruzzante et al., 2006; O'Leary et al., 2007; Pecoraro et al., 2016, 2018; Ruggeri et al., 2016a; 2016b).

Swordfish is a pelagic and highly migratory species, distributed worldwide from $45^{\circ} \mathrm{N}$ to $45^{\circ} \mathrm{S}$ in the open waters of the Atlantic, Indian, and Pacific oceans. Swordfish also occurs in the Mediterranean, Marmara, Black and Azov seas (Palko, Beardsley \& Richards, 1981). The 2011 International Union for the Conservation of Nature (IUCN) assessment for this species has shown a $28 \%$ decline in total biomass over the last 20 years globally, and the Mediterranean stock is currently overfished and not well-managed (Collette et al., 2011). The 2016 International Commission for the Conservation of Atlantic Tunas(ICCAT) Mediterranean swordfish stock assessment (2016) reported that the Mediterranean swordfish spawning stock biomass (SSB) level is less than $15 \%$ of biomass at maximum sustainable yield, and between 50 and $70 \%$ of total yearly catches were represented by small-sized individuals (Anon., 2019). For management purposes, ICCAT considers populations in the Mediterranean Sea, North Atlantic, and South Atlantic populations as three separate stocks.

Differentiation also occurs in biology with the Mediterranean swordfish having different characteristics compared to the Atlantic stocks such as a lower growth rate and younger age at sexual maturity than in the Atlantic populations (Cavallaro, Potoschi \& Cefali, 1991; Ehrhardt, 1992; Tserpes \& Tsimenides, 1995; Arocha, 2007). Moreover, genetic studies have confirmed genetic differentiation among the Atlantic and Mediterranean stocks (Bremer, Baker \& Mejuto, 1995; Kotoulas et al., 1995, 2007; Bremer et al., 1996; Rosel \& Block, 1996; Pujolar, Roldan \& Pla, 2002; Viñas et al., 2007). Separate analyses using mitochondrial and nuclear markers have 
78 highlighted a high level of genetic differentiation among the Atlantic and Mediterranean

79 populations (see Bremer et al., 2007 for a summary).

80 Differences among these basins were also observed in terms of discrete spawning areas, as well

81 as different spawning periods (Neilson et al., 2013). In the North Atlantic, reproduction takes

82 place in the western subtropical area, with year-round spawning and seasonal peaks (Arocha,

83 2007). In the Mediterranean Sea, spawning takes place between June and August (Palko,

84 Beardsley \& Richards, 1981; Arocha, 2007; Marisaldi et al., 2020) and it is restricted to three

85 main spawning grounds. The first is located in the western Mediterranean, from the Strait of

86 Gibraltar up to the Balearic Islands (Arocha, 2007; Neilson et al., 2013); the second one extends

87 from the Strait of Messina to the Gulf of Taranto in the Ionian Sea (Cavallaro, Potoschi \& Cefali,

88 1991; Arocha, 2007). The last one is close to Rhodes and Cyprus islands in the Levantine Sea

89 (Tserpes, Peristeraki \& Somarakis, 2001; Tserpes, Peristeraki \& Valavanis, 2008) (Figure 1).

90 Philopatric behaviour has been proposed as the driving force behind global swordfish structuring

91 and high levels of genetic differentiation between separate breeding areas, support the

92 assumption of spawning site fidelity in the Atlantic Ocean (Bremer et al., 2005a). Moreover, no

93 evidence of gene flow was observed using mtDNA between Mediterranean and North Atlantic

94 swordfish populations despite mixing in the feeding area to the west of the Strait of Gibraltar

95 (Bremer et al., 2007; Viñas et al., 2007).

96 While there are several studies on the global genetic structure of swordfish, few have focused on

97 the Mediterranean swordfish stock. Some of these studies suggest the occurrence of a

98 homogeneous stock in the Mediterranean Sea (RFLP of the entire mitochondrial DNA, Kotoulas

99 et al., 1995; RFLP of the mitochondrial control region and the nuclear Calmodulin gene, Chow

100 and Takeyama, 2000; four microsatellites, Kotoulas et al., 2007). Conversely, Viñas (2010) used

101 the analysis of mtDNA CR-I sequences to propose the existence of at least two distinct

102 Mediterranean populations: one in the eastern basin and the other in the western basin. Although

103 less evident, this pattern was detected using allozyme data (Pujolar, Roldan \& Pla, 2002). These

104 conflicting results regarding the occurrence of a genetic structure for the Mediterranean

105 population of swordfish suggest the need for thorough genetic studies focusing on this basin to

106 shed light on Mediterranean swordfish population structure and to provide reliable evidence for

107 management actions. In the present study, a multi-locus approach based on the screening of a

108 panel of 20 microsatellites was used to investigate the fine-scale genetic structure of swordfish

109 within the Mediterranean Sea. Sampling coverage differs from all previous genetic studies by

110 offering a more comprehensive representation of the Mediterranean area. In addition, the genetic

111 differentiation between Atlantic and Mediterranean swordfish populations was investigated.

112

113 Materials \& Methods

114 Sampling and DNA extraction

115 A total of 298 swordfish were collected from six areas within the eastern, central and western

116 Mediterranean regions, to obtain a representative coverage of the basin. Twenty-five swordfish

117 from the eastern coast of Canada have been included in the analysis as a comparison (For details

Peer] reviewing PDF | (2020:01:44647:3:0:NEW 15 Jun 2020) 
118

119

120

121

122

123

124

125

126

127

128

129

130

131

132

133

134

135

136

137

138

139

140

141

142

143

144

145

146

147

148

149

150

151

152

153

154

155

156

157

see Table 1 and Figure 1). Samples were collected at the fishing landing of the commercial catch by longline or trap bycatch (only in the case of Sardinian samples) from May to October in three years 2016-2018. Since sampling occurred on commercial landings, no young-of-the-year individuals (Lower jaw fork length $(\mathrm{LJFL})=60-70 \mathrm{~cm}$ ) were collected. Fish LJFL ranged from $81 \mathrm{~cm}$ to $236 \mathrm{~cm}$. For each sample, a piece of the caudal fin or muscle tissue was collected and stored in ethanol absolute and kept at $-20^{\circ} \mathrm{C}$ until DNA extraction. The procedures did not include animal experimentation, and ethics approval was not necessary following the Italian legislation (D.L. 4 of Mars 2014, n. 26, art. 2). Total genomic DNA was extracted using specific cartridge 401 in the MagCore ${ }^{\circledR}$ automated Nucleic Acid extractor (MagCore ${ }^{\circledR}$, Genomic DNA Tissue Kit, $n^{\circ} 401$ ) following the manufacturers' protocols.

\section{Microsatellite amplification, genotyping and diversity analysis}

All specimens were genotyped for 20 microsatellite loci: three from Muths et al. (2009): D2A, D2B, C8, eleven from Kasapidis et al. (2009): XgSau98R1, Xgl-14, Xgl-35, Xgl-65b, Xgl-74, Xgl-94, Xgl-106, Xgl-121, Xgl-148b, Xgl-523b, Xgl-561) and six from Reeb et al. (2003): Xg56, Xg-66, Xg-144, Xg-166, Xg-394, Xg-402). The PCR amplifications were performed combining microsatellite loci in five multiplex reactions based on primer's annealing temperature (details are shown in table 2). The PCR amplification conditions consisted of: $1 \times$ MyTaq Reaction buffer (Bioline) $\left(15 \mathrm{mmol} \cdot \mathrm{L}^{-1} \mathrm{MgCl}_{2}, 1,25 \mathrm{mmol} \cdot \mathrm{L}^{-1}\right.$ of each dNTP, plus stabilizers and enhancers), $0.3 \mu \mathrm{M}$ of each primer, 0.2 U Taq DNA polymerase (MyTaq, Bioline) and 40-80 ng of genomic DNA in a final volume of $10 \mu \mathrm{L}$ for 2- and 3-plex and $15 \mu \mathrm{L}$ for 4- and 7-plex, respectively. Each forward primer was labelled with a different fluorescent dye (FAM, VIC, NED, and PET) and set up avoiding the overlap of similar allele sizes. PCR conditions were optimized for all loci using the following touchdown protocol: initial denaturation at $95^{\circ} \mathrm{C}$ for 5 minutes, followed by 10 cycles of denaturation at $92^{\circ} \mathrm{C}$ for 20 seconds, annealing at the specific temperature (Ta) (Table 2) for 30 seconds, and extension at $72^{\circ} \mathrm{C}$ for 45 seconds. At each cycle, the annealing temperature decreased by $0.5^{\circ} \mathrm{C}$. After that, samples were subjected to an additional 25 cycles of denaturation at $90^{\circ} \mathrm{C}$ for 30 seconds, annealing at $\left[\mathrm{Ta}-5^{\circ} \mathrm{C}\right]$ for 50 seconds, and extension at $72^{\circ} \mathrm{C}$ for 55 seconds. The reaction finished with a final elongation at $72^{\circ} \mathrm{C}$ for 5 minutes. Amplified fragments were separated by electrophoresis using ABI Prism 3130xl genetic analyser executed by BMR-Genomics (Padua). Alleles were scored using GS 500LIZ_3130 size standard using Peakscanner 2 (Applied Biosystems), and the outputs were manually evaluated. The binning of alleles was accomplished using Flexibin 2 (Amos et al., 2007), to minimize microsatellite alleles miscalling.

Micro-Checker 2.2.3 (Van Oosterhout et al., 2003) was employed to test for genotyping errors due to stuttering, allelic dropout and the presence of null alleles. FreeNA (Chapuis \& Estoup, 2006) was used to estimate if the presence of null alleles affected $F_{S T}$ estimation. Therefore, global $\mathrm{F}_{\mathrm{ST}}$ was calculated by both including null alleles (INA) and excluding null alleles (ENA). The bootstrap $95 \%$ confidence intervals (CI) for the global $\mathrm{F}_{\mathrm{ST}}$ values were calculated using 50,000 replicates over all loci. Allelic richness $(A R)$, which is a standardised index of the mean number of alleles per locus irrespective of sample size, was estimated using Fstat 2.9.3 (Goudet, 
158

159

160

161

162

163

164

165

166

167

168

169

170

171

172

173

174

175

176

177

178

179

180

181

182

183

184

185

186

187

188

189

190

191

192

193

194

195

196

197

2001). Observed $\left(H_{\mathrm{o}}\right)$ and expected $\left(H_{\mathrm{e}}\right)$ heterozygosity was computed with Arlequin v. 3.5.2.2 (Excoffier \& Lischer, 2010). The Fisher's exact test was performed to evaluate deviation from Hardy-Weinberg equilibrium for each population and each locus using Genepop online software (Raymond \& Rousset, 1995). The same software was also used to test linkage disequilibrium (LD) for all pairs of loci. Exact P-values were estimated using the Markov Chain algorithm (10,000 dememorization steps, 100 batches and 5,000 iterations) and the significance of HWE and LD values were adjusted with Bonferroni correction.

\section{Population structure analysis}

Global $F_{\text {ST }}$ values (Weir \& Cockerham, 1984) were analysed using Fstat 2.9.3. The 95\% C.I. was estimated on 1000 iterations. Pairwise $\mathrm{F}_{\mathrm{ST}}$ distances among sampling localities were estimated in Arlequin 3.5.2.2 using 10000 permutations $(p<0.001)$. Furthermore, both the Bayesian clustering method implemented in STRUCTURE 2.3.4 (Pritchard et al., 2000) and the Discriminant Analysis of Principal Components (DAPC) (Jombart, Devillard \& Balloux, 2010) were used to find the number of discrete genetic populations. The two clustering approaches were used in this study to compare the results. Different clustering approaches may lead to different conclusions (Latch et al., 2006; Waples \& Gaggiotti, 2006; Frantz et al., 2009; Kanno, Vokoun \& Letcher, 2011). DAPC, unlike STRUCTURE, does not rely on a specific population genetic model, and it is, therefore, free of assumptions about Hardy-Weinberg equilibrium or linkage disequilibrium. The absence of any assumption about the underlying population genetics model is one of the main assets of DAPC analysis, that results more suitable to unravel structuring in more complex population genetic models and may be more efficient at identifying genetic cline and hierarchical structure (Jombart, Devillard \& Balloux, 2010). The Bayesian analysis (STRUCTURE), carried out by using the microsatellite dataset, was based on 10 consecutive runs per cluster $(\mathrm{K})$ where $\mathrm{K}$ ranged between 1 and 7 . The admixture model and correlated allele frequencies model were set up. All analyses were run for $5 \times 10^{5}$ generations after a burn-in of $10 \times 10^{4}$ generations. The number of clusters that best fit the observed genotype data was determined comparing deltaK $(\Delta \mathrm{K})$ (Evanno, Regnaut \& Goudet, 2005) and the mean logarithmic probability of $\mathrm{K}, \mathrm{LnP}(\mathrm{K})$, using the StructureSelector website (Li \& Liu, 2018). The individual posterior probabilities of assignment $(q)$ to specific cluster were estimated. The DAPC analysis was executed using package adegenet (Jombart, 2008). The firstly an explorative analysis was performed including apriori sampling geographical information to visualise the relationship between sampling locations. Cross-validation was used to select the number of principal components (PCs) to retain for DAPC. The lowest number of components for which the correct assignment probability stabilized was 40. Secondly, the optimal number of clusters $(\mathrm{K})$ was evaluated with the function find.cluster which runs successive rounds of kmeans clustering with an increasing number of clusters ( $\mathrm{K}$ ranged from 1 to 5 ) and 500 runs at each value of K. Bayesian information criterion (BIC) was used to select the optimal number of clusters. Ideally, the lowest BIC value represents the optimal number of clusters, but, BIC values may keep decreasing after the true $\mathrm{K}$ value in the presence of genetic clines and hierarchical structure (Jombart, Devillard \& Balloux, 2010). To choose the best number of $\mathrm{K}$, the subdivision 
198

199

200

201

202

203

204

205

206

207

208

209

210

211

212

213

214

215

216

217

218

219

220

221

222

223

224

225

226

227

228

229

230

231

232

233

234

235

236

237

of individuals was investigated for $\mathrm{K}$ from 2 to 5 . The analysis was performed both including and excluding the Canadian sample. Finally, pairwise $F_{S T}$ values among the best number of genetic clusters detected by DAPC were calculated in Arlequin.

\section{Results}

\section{Microsatellite genetic diversity}

Twenty microsatellite loci were amplified for all 323 swordfish samples. The PCR failure per locus ranged between 0 and $5.9 \%$, with an average of $1.1 \%$.

Significant deviations from Hardy-Weinberg equilibrium were detected in 18 out of 140 single locus exact tests at loci Xgl-94, Xgl-74, Xgl-14, Xg66 and Xg166 (Table S1), considering sampling localities separately. Pooling together Mediterranean swordfish, 5 out of 20 loci deviated significantly from Hardy-Weinberg equilibrium (Xg1-94, Xgl-74, Xgl-14, Xg66, Xgl523). All deviations were towards a heterozygote deficit. Micro-checker showed evidence of null alleles (frequency $>0.3$ ) for Xgl-74 and Xg-66. These loci deviated from Hardy-Weinberg equilibrium in many populations, including the Canadian samples and were, therefore, removed from further analysis. Rarer null alleles at Xgl-94, Xgl-14 and Xg166 were detected. However, these latter loci were retained because the presence of null alleles did not bias the population differentiation parameters. In fact, the estimation of $\mathrm{F}_{\mathrm{ST}}$, including and excluding the ENA correction method gave comparable results; $\mathrm{F}_{\mathrm{ST}}=0.018$ with the respective $95 \% \mathrm{CI}$ [0.0110.027]. No consistent evidence for linkage disequilibrium was detected between pairs of loci within populations.

All the remaining 18 loci were polymorphic, with the number of alleles per locus ranging from two at locus Xg-402, to 21 at locus C8. Both, Xg-402 (two alleles) and Xg-394 (three alleles) loci were monomorphic in three samples GRE, SPA and CAN. The Mediterranean samples exhibited a significantly lower number of alleles per locus, allelic richness, and expected heterozygosity, compared to the Atlantic samples (Table 3 and S1). Instead, the mean number of alleles and their level of heterozygosity resulted similar among Mediterranean samples. Thus, no evidence of a geographical pattern was observed for the distribution of genetic variability among Mediterranean samples.

\section{Genetics Structure}

The global $\mathrm{F}_{\mathrm{ST}}$ showed a significant signal for genetic differentiation between Mediterranean and Atlantic populations $\left(\mathrm{F}_{\mathrm{ST}}=0.091 ; 95 \%\right.$ C.I. 0.056-0.133). The $\mathrm{F}_{\mathrm{ST}}$ values decreased when considering the Mediterranean samples separately $\left(\mathrm{F}_{\mathrm{ST}}=0.018\right.$; $95 \%$ C.I. 0.011-0.027). Pairwise $\mathrm{F}_{\mathrm{ST}}$ across all samples ranged from 0 to 0.097 . Low and statistically not significant values were detected between Mediterranean localities, whereas the higher and significant values $(p<0.001)$ were observed when comparing the Mediterranean and Atlantic samples, $\mathrm{F}_{\mathrm{ST}}$ values ranging from 0.083 (CAN-GRE) to 0.097 (CAN-SAR). The Bayesian clustering analysis suggested the presence of two genetic clusters $(\mathrm{K}=2)$ using $\Delta \mathrm{K}$ method, while $\mathrm{LnP}(\mathrm{K})$ showed an increase to $\mathrm{K}=2$ before declining and subsequently increasing to $\mathrm{K}=6$ (Figure $2 \mathrm{~A}-\mathrm{B}$ ). For $\mathrm{K}=2$, individuals were partitioned according to their source basins (Mediterranean vs North-western 
238

239

240

241

242

243

244

245

246

247

248

249

250

251

252

253

254

255

256

257

258

259

260

261

262

263

264

265

266

267

268

269

270

271

272

273

274

275

276

Atlantic). Individuals were assigned to the specific cluster with a high score showing an average $q=0.98$ for the Mediterranean group and an average $q=0.95$ for the Atlantic group. Few individuals showed signs of mixing between groups (Figure 2C). Considering $\mathrm{K}=6$, Atlantic swordfish formed a single cluster, while all Mediterranean swordfish were uniformly assigned to the remaining five groups which failed in population structure identification (graph not shown). The exploratory multivariate analysis, considering a priori sampling groups, divided swordfish into two groups. The first discriminant component ( $81 \%$ of variance) distinguished between Atlantic and Mediterranean swordfish, clustering all Mediterranean sampling localities together. This result is consistent with inter-oceanic genetic differentiation (Figure 3).

Conversely, a posteriori assignment by DAPC analysis, despite the absence of a clear best value for the number of clusters, suggested the presence of more than two genetic clusters. The BIC graph showed an apparent decrease until $\mathrm{K}=4$, reaching a slightly lower value at $\mathrm{K}=5$ (Figure 4A). For $\mathrm{K}=2$ and 3 high numbers of Mediterranean specimens were assigned into the Atlantic cluster and was in contrast with interoceanic differentiation reported in literature, STRUCTURE and explorative DAPC results (Figure 4B, C, F). For $\mathrm{K}=4$, an evident interoceanic structure, in line with previous results, was detected (Figure 4D). All Atlantic individuals but two clustered into a single group while Mediterranean swordfish were subdivided into the remaining three groups. Mediterranean groups were randomly distributed among sampling localities, and no geographic pattern was observed (Figure 4F). Increasing the number of $\mathrm{K}$, increased admixture and mixing within the Mediterranean samples. Therefore, $\mathrm{K}=4$ was selected as the possible optimal number of groups. The DAPC analysis performed excluding the Canadian sample corroborated the previous result identifying $\mathrm{K}=3$ as the most probable number of clusters within the Mediterranean Sea (Figure 5). All pairwise $\mathrm{F}_{\mathrm{ST}}$ comparisons among clusters detected by the DAPC were statistically significant. Higher values were reported comparing Cluster 4 (Atlantic samples) among Mediterranean clusters: $1\left(\mathrm{~F}_{\mathrm{ST}}=0.13\right), 2\left(\mathrm{~F}_{\mathrm{ST}}=0.09\right)$, and $3\left(\mathrm{~F}_{\mathrm{ST}}=0.11\right)$. Among Mediterranean genetic groups, pairwise $\mathrm{F}_{\mathrm{ST}}$ ranged from 0.05 (cluster 1- cluster 3) to 0.07 (cluster 2- cluster 3).

\section{Discussion}

This study aimed to investigate the genetic structure of the swordfish Xiphias gladius, within the Mediterranean Sea and between NW-Atlantic and Mediterranean populations using a panel of 18 polymorphic microsatellite loci. These results indicate clear inter-oceanic genetic differentiation among NW-Atlantic and Mediterranean stocks with an improved ability to assign individuals to their population of origin compared to previous multi-locus works (Kotoulas et al., 2007; Smith et al., 2015). Secondly, conversely to previous studies, the multivariate analysis based on microsatellite dataset suggested the presence of three mixed genetic groups within the Mediterranean Sea.

Before examining the results, we must address the mains caveat of this study: sampling sites. The samples for this study were collected opportunistically. Therefore we cannot evaluate 
277 hypothesis related to putative homing of the species towards breeding areas or to evaluate 278 admixture in the feeding locations.

279 The Mediterranean population showed a lower level of genetic variability compared to Atlantic 280 ones, corroborating the outcomes of previous studies based on microsatellites (Reeb, Arcangeli 281 \& Block, 2003; Kotoulas et al., 2007; Kasapidis et al., 2009) and mtDNA (Bremer et al., 1995, 282 1996, 2005b; Kotoulas et al., 1995; Rosel and Block, 1996). The low genetic variability and 283 small effective population size of the Mediterranean swordfish population could be a 284 consequence of the semi-enclosed nature and the limited size of the Mediterranean basin 285 (Bremer et al., 2005b; Kasapidis et al., 2007).

286 The dataset allowed to clearly identify a genetic structure between the Mediterranean and 287 Atlantic populations according to previous studies (Bremer, Baker \& Mejuto, 1995; Kotoulas et 288 al., 1995, 2007; Bremer et al., 1996; Rosel \& Block, 1996; Pujolar, Roldan \& Pla, 2002; Viñas et 289 290

291

292

293

294

295

296

297

298

299

300

301

302

303

304

305

306

307

308

309

310

311

312

313

314

315

316 al., 2007, Smith et al., 2015). The presence of these populations is supported by pairwise $F_{S T}$, multivariate analysis (DAPC) and Bayesian genetic clustering using STRUCTURE. However, the estimates of differentiation $\left(\mathrm{F}_{\mathrm{ST}}\right)$ calculated in this work between the two stocks $(0.091)$, is higher than those reported by recent works also using a multi-locus approach (Kotoulas et al., 2007; Smith et al., 2015). A low $\mathrm{F}_{\mathrm{ST}}$ value $\left(\mathrm{F}_{\mathrm{ST}}<0.03\right)$ was reported between Atlantic and Mediterranean swordfish stocks using four highly polymorphic microsatellites (Kotoulas et al., 2007), while $F_{S T}$ values around 0.07 were reported by Smith et al.(2015) analysing 26 single nucleotide polymorphisms (SNPs) within 10 nuclear genes. Moreover, Smith et al. (2015), by using this approach, effectively distinguished the population of the North Atlantic from that of the South Atlantic unlike previous efforts based on 4 microsatellites (Kasapidis et al., 2007; Kotoulas et al., 2007). The greater Fst observed in this study likely results from the greater number of loci analysed, which could enhance the resolution and improve the precision of estimates of genetic distance (Nei, 1978; Kalinowski, 2005).

Although both STRUCTURE and DAPC identify interoceanic genetic differentiation, the results obtained from STRUCTURE clustering methods using microsatellites were not concordant, with DAPC providing evidence. DAPC, in fact, provided evidence of a substructure inside the Mediterranean Sea. The discrepancy between clustering methods may be attributable to the model-based methods employed. Bayesian methods typically fail to identify some complex types of spatial structure such as isolation-by-distance (Jombart, Devillard \& Balloux, 2010) and hierarchical population structure (Evanno, Regnaut \& Goudet, 2005), and fail to detect any genetic structure when genetic divergence is very low $\left(\mathrm{F}_{\mathrm{ST}}<0.03\right)$ (Latch et al., 2006; Waples \& Gaggiotti, 2006; Duchesne \& Turgeon, 2012). On the other hand, the ability of DAPC to identify genetic clusters when STRUCTURE failed was reported by Jombart et al. (2010) and Kanno et al. (2011). Thus, DAPC can outperform the STRUCTURE method in inferring the number of subpopulations when they are weakly differentiated as in our study case.

In the present study, the Mediterranean swordfish display a week but significant structure where clusters, detected by DAPC, are spatially admixed with no geographic pattern; a result corroborated by pairwise $\mathrm{F}_{\mathrm{ST}}$ estimation. Population structure within the Mediterranean Sea is

Peer) reviewing PDF | (2020:01:44647:3:0:NEW 15 Jun 2020) 
317 not consistent with previous work based on microsatellite data (Kotoulas et al., 2007). However, 318 Kotoulas et al. (2007) analysed only four microsatellites; a very low number of loci with which 319 to attempt to detect the presence of genetic differentiation, especially in the case of pelagic fish

320

321

322

323

324

325

326

327

328

329

330

331

332

333

334

335

336

337

338

339

340

341

342

343

344

345

346

347

348

349

350

351

352

353

354

355

356

species. Genetic homogeneity across Mediterranean sampling localities was, also, observed by previous studies based on allozymes data (Pujolar, Roldan \& Pla, 2002), RFLPs of the entire mtDNA (Chow et al., 1997), analyses of a single-copy nuclear calmodulin gene and PCR-RFLP data of the mtDNA CR (Chow \& Takeyama, 2000). However, sample homogeneity does not necessarily equate to population homogeneity (Ward, 2000) and population differentiation may be obscured by population mixture in wintering or feeding areas, especially for highly migratory species (Van Wagner \& Baker, 1990; Bowen et al., 1992; Wenink, Baker \& Tilanus, 1993; Bremer et al., 2005a). Swordfish is a highly migratory species, and in the Atlantic Ocean, it is able to cover annually very long distances as reported by pop-up satellite archival tags analysis (Neilson et al., 2014; Abascal et al., 2015). The same ability was also observed within the Mediterranean Sea (Canese et al., 2008). Evidence of shared areas has been observed in the feeding area west of the Strait of Gibraltar where Mediterranean and North Atlantic swordfish populations mix (Bremer et al., 2005a; Viñas et al., 2007; Smith et al., 2015). Furthermore, admixture between North and South Atlantic populations occurs over a broader geographic area from Western Sahara to the Iberian sea extending west towards the central North Atlantic and then south towards the northern Brazilian coast (Smith et al., 2015). Considering each of the Mediterranean sampling areas we note that no evidence of spawning activities has been observed in the Adriatic Sea, (Arocha, 2007) and it is unlikely that a mixture of individuals originating from different subpopulations would ever result as a consequence of a transitional effect due to its semi-enclosed sea characteristic. Rather, individual admixture in the Adriatic Sea is likely a consequence of its use as a feeding ground. As for the other sampling areas, they could represent transitional zones with mixing between populations as occurs between North and South Atlantic swordfish. The hypothesis of an admixed population within the Mediterranean Sea is also supported by the significant excess of homozygote genotypes detected in Mediterranean samples (Table 4 and S1). An excess of homozygotes may be due to genotyping errors such as null alleles, allele dropout and stuttering, or it can be a consequence of inappropriate sample size. However, a biological explanation for the occurrence of Hardy Weinberg disequilibrium (HWD) is known as the Wahlund effect (WE). According to the WE, HWD can appear to occur when the sample analysed is composed of a mix of distinct subpopulations, as would be expected by highly migratory and spatially structured species.

Philopatric behaviour has been identified as the driving force behind the structuring of very high migratory pelagic fish Istiompax indica (Williams et al., 2016), Gadus morhua (Bonanomi et al., 2016) and Thunnus thynnus (Rooker et al., 2008; Aranda et al., 2013). In swordfish, spawning site fidelity is supported by both high levels of genetic differentiation obtained comparing separated breeding areas in the Atlantic Ocean (Bremer et al., 2005a, 2007) and the evidence of the mixing areas with minimal gene flow between Mediterranean and North Atlantic swordfish populations (Bremer et al., 2007; Viñas et al., 2007; Smith et al., 2015). Seasonal site (foraging

Peer) reviewing PDF | (2020:01:44647:3:0:NEW 15 Jun 2020) 
357

358

359

360

361

362

363

364

365

366

367

368

369

370

371

372

373

374

375

376

377

378

379

380

381

382

383

384

385

386

387

388

389

390

391

392

393

394

395

396

and spawning) fidelity was also suggested within the Mediterranean Sea by the recapture of tagged individuals, that generally occurred in the same area of tagging also after several years (Garibaldi \& Lanteri, 2017). Philopatric instinct was already suggested byViñas et al. (2010) as a possible cause of swordfish population differentiation within the Mediterranean Sea. The authors suggested population substructure based on a clinal decrease in mitochondrial genetic variability from the western to the eastern basins. They hypothesised that population differentiation may be the consequence of distinct phylogeographic histories of populations in the Eastern and the Western Mediterranean basins and is maintained by present-day life-history traits, including homing fidelity to spawning sites. Within the Mediterranean Sea, three main spawning areas are currently recognized. The first one is located in the western part of the basin, the second one in the eastern part and the third one extends from the southern Tyrrhenian Sea to the Ionian Sea (Cavallaro, Potoschi \& Cefali, 1991; Tserpes, Peristeraki \& Somarakis, 2001; Arocha, 2007; Tserpes, Peristeraki \& Valavanis, 2008). Although there is no evidence that these spawning aggregations represent discrete stocks, geographical localization of these three discrete spawning areas may explain the three genetic clusters observed in this study. However, the sampling design used in this study does not allow us to test this hypothesis.

Rejection of a model of panmixia in a relatively small sea basin is not new for large pelagic species. For example, for the Atlantic bluefin tuna (ABFT), which shares the same spawning grounds as swordfish (Bonales et al., 2019), a remarkable homing behaviour to Tyrrhenian and Ionian spawning grounds has been detected by satellite tracks (Reeb, 2010). Reproductive isolation explains a fine-scale structure identified among Balearic, Tyrrhenian, and Ionian juvenile bluefin tuna using both nuclear microsatellite loci and the mtDNA control region (Carlsson et al., 2004). Furthermore, spatially and temporally stable genetic structure was observed between Adriatic and Tyrrhenian bluefin tuna (Riccioni et al., 2010).

\section{Conclusions}

The present study suggests genetic heterogeneity within the Mediterranean Sea swordfish stock supporting previous study (Viñas et al. 2010). Despite the low differentiation observed, these results provide useful information on the stock structure of the swordfish, contributing evidence for the rejection of the hypothesis for a single Mediterranean population. The high degree of separation between Mediterranean spawning areas of swordfish towards these areas could support a weak degree of genetic differentiation. Although weakly differentiated, the presence of genetically distinct clusters warrants reconsidering the appropriateness of the current single-stock approach used by ICCAT. Management recommendations and measures which assume stock uniformity across large regions may result in overfishing of some small, but discrete demographic units. However, the high level of mixing at sample locations hampers a clear delineation into corresponding spatial management areas. In light of these results, further investigations are required to determine the degree of complexity of the Mediterranean swordfish population structure to achieve effective swordfish conservation. To date, significant gaps still exist regarding Mediterranean swordfish life history and stock structure. Including in the analysis

Peer] reviewing PDF | (2020:01:44647:3:0:NEW 15 Jun 2020) 
397 larvae and young-of-the-year (YOY) would assist in the assessment of swordfish population 398 dynamics. Collecting a larger sample size from each spawning grounds, maximizing stock 399 discreteness could ameliorate the evaluation of geographic genetic segregation. Moreover, 400 including tagging information, currently very limited for Mediterranean swordfish, would be

401

402

403

404

405

406

407

408

409

410

411

412

413

414

415

416

417

418

419

420

421

422

423

424

425

426

427

428

429

430

431

432

433

434

435 necessary to better resolve the swordfish migratory behaviour.

\section{Acknowledgements}

We truly thank the fishermen, Pesca Pronta Import-Export s.r.l. for their extremely precious collaboration during sampling activities. The authors wish to thank all the staff at OCEANIS s.r.l. (Ercolano, Naples) and Dr Alessandro Lucchetti (ISMAR-CNR, Ancona) for the support in sampling activities. We also thank Tom Jenkins (https://github.com/Tom-Jenkins) and BJ Knaus, and NJ Grünwald (https://grunwaldlab.github.io/Population_Genetics in_R/clustering_plot.html) for the R scripts for graphical results representation.

\section{References}

Abascal FJ, Mejuto J, Quintans M, García-Cortés B, Ramos-Cartelle A. 2015. Tracking of the broadbill swordfish, Xiphias gladius, in the central and eastern North Atlantic. Fisheries Research 162:20-28.

Amos W, Hoffman JI, Frodsham A, Zhang L, Best S, Hill AVS. 2007. Automated binning of microsatellite alleles: problems and solutions. Molecular Ecology Notes 7:10-14.

Anon. 2019. Report for biennial period, 2018-19 PART I (2018) - Vol. 2. Madrid, Spain: International Commission for the Conservation of Atlantic Tunas. Aranda G, Abascal FJ, Varela JL, Medina A. 2013. Spawning behaviour and post-spawning migration patterns of Atlantic bluefin tuna (Thunnus thynnus) ascertained from satellite archival tags. PloS one 8:e76445.

Arocha F. 2007. Swordfish Reproduction in the Atlantic Ocean: An Overview. Gulf and Caribbean Research 19. DOI: 10.18785/gcr.1902.05.

Bonales JV, Cañadas A, Tensek S, García AP, Alemany F. 2019. ICCAT GBYP aerial survey for bluefin tuna spawning aggregations in 2018. Collect. Vol. Sci. Pap. ICCAT 75:1525-1544. Bonanomi S, Overgaard Therkildsen N, Retzel A, Berg Hedeholm R, Pedersen MW, Meldrup D, Pampoulie C, Hemmer-Hansen J, Grønkjær P, Nielsen EE. 2016. Historical DNA documents long-distance natal homing in marine fish. Molecular Ecology 25:2727-2734.

Bowen BW, Meylan AB, Ross JP, Limpus CJ, Balazs GH, Avise JC. 1992. Global population structure and natural history of the green turtle (Chelonia mydas) in terms of matriarchal phylogeny. Evolution 46:865-881.

Bremer JRA, Baker AJ, Mejuto J. 1995. Mitochondrial DNA control region sequences indicate extensive mixing of swordfish (Xiphias gladius) populations in the Atlantic Ocean. Canadian Journal of Fisheries and Aquatic Sciences 52:1720-1732. 
436 Bremer JA, Mejuto J, Gómez-Márquez J, Boán F, Carpintero P, Rodríguez JM, Viñas J, Greig 437 TW, Ely B. 2005a. Hierarchical analyses of genetic variation of samples from breeding and 438 feeding grounds confirm the genetic partitioning of northwest Atlantic and South Atlantic 439 populations of swordfish (Xiphias gladius L.). Journal of Experimental Marine Biology and 440 Ecology 327:167-182.

441 Bremer JA, Mejuto J, Gómez-Márquez J, Pla-Zanuy C, Viñas J, Marques C, Hazin F, Griffiths 442 M, Ely B, García-Cortés B. 2007. Genetic population structure of Atlantic swordfish: current 443 status and future directions. ICCAT Collect. Vol. Sci. Pap. 61:107-118.

444 Bremer JRA, Mejuto J, Greig TW, Ely B. 1996. Global population structure of the swordfish 445 (Xiphias gladius L.) as revealed by analysis of the mitochondrial DNA control region. Journal of 446 Experimental Marine Biology and Ecology 197:295-310.

447 Bremer JRA, Viñas J, Mejuto J, Ely B, Pla C. 2005b. Comparative phylogeography of Atlantic 448 bluefin tuna and swordfish: the combined effects of vicariance, secondary contact, introgression, 449 and population expansion on the regional phylogenies of two highly migratory pelagic fishes. 450 Molecular phylogenetics and evolution 36:169-187.

451 Canese S, Garibaldi F, Relini LO, Greco S. 2008. Swordfish tagging with pop-up satellite tags in 452 the Mediterranean Sea. Collect. Vol. Sci. Pap. ICCAT 62:1052-1057.

453 Carlsson J, McDowell JR, Díaz-Jaimes P, Carlsson JE, Boles SB, Gold JR, Graves JE. 2004. 454 Microsatellite and mitochondrial DNA analyses of Atlantic bluefin tuna (Thunnus thynnus 455 thynnus) population structure in the Mediterranean Sea. Molecular Ecology 13:3345-3356.

456 Cavallaro G, Potoschi A, Cefali A. 1991. Fertility gonad-somatic index and catches of eggs and 457 larvae of Xiphias gladius L. 1758 in the southern Tyrrhenian Sea. Col. Vol. Sci. Pap. ICCAT 458 35:502-507.

459 Chapuis M-P, Estoup A. 2006. Microsatellite null alleles and estimation of population 460 differentiation. Molecular biology and evolution 24:621-631.

461 Chow S, Takeyama H. 2000. Nuclear and mitochondrial DNA analyses reveal four genetically 462 separated breeding units of the swordfish. Journal of Fish Biology 56:1087-1098.

463 Cochrane KL. 2002. A Fishery Manager's Guidebook-Management Measures and Their 464 Application (Tech. No. 424). Rome: FAO.

465 Collette, B., Acero, A., Amorim, A.F., Bizsel, K., Boustany, A., Canales Ramirez, C., Cardenas, 466 G., Carpenter, K.E., de Oliveira Leite Jr., N., Di Natale, A., Die, D., Fox, W., Fredou, F.L., 467 Graves, J., Guzman-Mora, A., Viera Hazin, F.H., Hinton, M., Juan Jorda, M., Minte Vera, C., 468 Miyabe, N., Montano Cruz, R., Masuti, E., Nelson, R., Oxenford, H., Restrepo, V., Salas, E., 469 Schaefer, K., Schratwieser, J., Serra, R., Sun, C., Teixeira Lessa, R.P., Pires Ferreira Travassos, 470 P.E., Uozumi, Y. \& Yanez, E. 2011. Xiphias gladius (errata version published in 2016). The 471 IUCN Red List of Threatened Species 2011:

472 e.T23148A88828055. https://dx.doi.org/10.2305/IUCN.UK.2011-2.RLTS.T23148A9422329.en. 473 Downloaded on 17 December 2017.

474 Duchesne P, Turgeon J. 2012. FLOCK provides reliable solutions to the "number of 475 populations" problem. Journal of Heredity 103:734-743. 
476 Ehrhardt NM. 1992. Age and growth of swordfish, Xiphias gladius, in the northwestern Atlantic. 477 Bulletin of Marine Science 50:292-301.

478 Evanno G, Regnaut S, Goudet J. 2005. Detecting the number of clusters of individuals using the 479 software STRUCTURE: a simulation study. Molecular ecology 14:2611-2620.

480 Excoffier L, Lischer HE. 2010. Arlequin suite ver 3.5: a new series of programs to perform 481 population genetics analyses under Linux and Windows. Molecular ecology resources 10:564482567.

483 Frantz AC, Cellina S, Krier A, Schley L, Burke T. 2009. Using spatial Bayesian methods to 484 determine the genetic structure of a continuously distributed population: clusters or isolation by 485 distance? Journal of Applied Ecology 46:493-505.

486 Garibaldi F, Lanteri L. 2017. Notes about a tagged/recaptured swordfish in the Ligurian Sea 487 (western Mediterranean). Collective Volume of Scientific Papers, ICCAT 74:1354-1361. 488 Goudet J. 2001. FSTAT, a program to estimate and test gene diversity and fixation indices 489 (version 2.9.3). http://www2. unil. ch/popgen/softwares/fstat. htm.

490 Jombart T. 2008. adegenet: a R package for the multivariate analysis of genetic markers. 491 Bioinformatics 24:1403-1405.

492 Jombart T, Devillard S, Balloux F. 2010. Discriminant analysis of principal components: a new 493 method for the analysis of genetically structured populations. BMC genetics 11:94.

494 Kalinowski ST. 2005. Do polymorphic loci require large sample sizes to estimate genetic 495 distances? Heredity 94:33.

496 Kanno Y, Vokoun JC, Letcher BH. 2011. Fine-scale population structure and riverscape genetics 497 of brook trout (Salvelinus fontinalis) distributed continuously along headwater channel networks. 498 Molecular Ecology 20:3711-3729.

499 Kasapidis P, Mejuto J, Tserpes G, Antoniou A, Garcia-Cortes B, Peristeraki P, Oikonomaki K, 500 Kotoulas G, Magoulas A. 2007. Genetic structure of the swordfish (Xiphias gladius) stocks in 501 the Atlantic using microsatellite DNA analysis. Collect. Vol. Sci. Pap. ICCAT 61:89-98.

502 Kasapidis P, Pakaki V, Kotoulas G, Magoulas A. 2009. Isolation and characterization of 18 new 503 polymorphic microsatellite loci for the swordfish, Xiphias gladius. Molecular ecology resources 504 9:1383-1386.

505 Kotoulas G, Magoulas A, Tsimenides N, Zouros E. 1995. Marked mitochondrial DNA 506 differences between Mediterranean and Atlantic populations of the swordfish, Xiphias gladius. 507 Molecular Ecology 4:473-482.

508 Kotoulas G, Mejuto J, Antoniou A, Kasapidis P, Tserpes G, Piccinetti C, Peristeraki P, Garcia509 Cortes B, Oikonomaki K, De la Serna JM. 2007. Global genetic structure of swordfish (Xiphias 510 gladius) as revealed by microsatellite DNA markers. ICCAT Coll Vol Sci Pap 61:79-88.

511 Latch EK, Dharmarajan G, Glaubitz JC, Rhodes OE. 2006. Relative performance of Bayesian 512 clustering software for inferring population substructure and individual assignment at low levels 513 of population differentiation. Conservation Genetics 7:295-302.

514 Li Y-L, Liu J-X. 2018. StructureSelector: A web-based software to select and visualize the 515 optimal number of clusters using multiple methods. Molecular Ecology Resources 18:176-177. 
516 Marisaldi L, Basili D, Candelma M, Sesani V, Pignalosa P, Gioacchini G, Carnevali O. 2020.

517 Maturity assignment based on histology-validated macroscopic criteria: Tackling the stock

518 decline of the Mediterranean swordfish (Xiphias gladius). Aquatic Conservation: Marine and

519 Freshwater Ecosystems 30:303-314.

520 Martínez P, González EG, Castilho R, Zardoya R. 2006. Genetic diversity and historical

521 demography of Atlantic bigeye tuna (Thunnus obesus). Molecular phylogenetics and evolution

522 39:404-416.

523 Muths D, Grewe P, Jean C, Bourjea J. 2009. Genetic population structure of the Swordfish

524 (Xiphias gladius) in the southwest Indian Ocean: Sex-biased differentiation, congruency between

525 markers and its incidence in a way of stock assessment. Fisheries Research 97:263-269.

526 Nei M. 1978. Estimation of average heterozygosity and genetic distance from a small number of

527 individuals. Genetics 89:583-590.

528 Neilson J, Arocha F, Cass-Calay S, Mejuto J, Ortiz M, Scott G, Smith C, Travassos P, Tserpes

529 G, Andrushchenko I. 2013. The recovery of Atlantic swordfish: the comparative roles of the

530 regional fisheries management organization and species biology. Reviews in Fisheries Science

531 21:59-97.

532 Neilson JD, Loefer J, Prince ED, Royer F, Calmettes B, Gaspar P, Lopez R, Andrushchenko I.

533 2014. Seasonal distributions and migrations of Northwest Atlantic swordfish: inferences from

534 integration of pop-up satellite archival tagging studies. PLoS One 9:e112736.

535 O'Leary DB, Coughlan J, Dillane E, McCarthy TV, Cross TF. 2007. Microsatellite variation in

536 cod Gadus morhua throughout its geographic range. Journal of Fish Biology 70:310-335.

537 Palko BJ, Beardsley GL, Richards WJ. 1981. Synopsis of the biology of the swordfish, Xiphias

538 gladius Linnaeus.

539 Pecoraro C, Babbucci M, Franch R, Rico C, Papetti C, Chassot E, Bodin N, Cariani A,

540 Bargelloni L, Tinti F. 2018. The population genomics of yellowfin tuna (Thunnus albacares) at

541 global geographic scale challenges current stock delineation. Scientific reports 8:13890.

542 Pecoraro C, Babbucci M, Villamor A, Franch R, Papetti C, Leroy B, Ortega-Garcia S, Muir J,

543 Rooker J, Arocha F. 2016. Methodological assessment of 2b-RAD genotyping technique for

544 population structure inferences in yellowfin tuna (Thunnus albacares). Marine genomics 25:43-

54548.

546 Puechmaille SJ. 2016. The program structure does not reliably recover the correct population

547 structure when sampling is uneven: subsampling and new estimators alleviate the problem.

548 Molecular Ecology Resources 16:608-627.

549 Pujolar JM, Roldan MI, Pla C. 2002. A genetic assessment of the population structure of 550 swordfish (Xiphias gladius) in the Mediterranean Sea. Journal of Experimental Marine Biology 551 and Ecology 276:19-29.

552 Raymond M, Rousset F. 1995. GENEPOP on the Web (Version 3.4). URL: http://wbiomed.

553 curtin. edu. au/genepop/Updated from Raymond \& Rousset.

554 Reeb CA. 2010. Genetic discontinuity of big fish in a small sea. Proceedings of the National

555 Academy of Sciences 107:2377-2378. 
556 Reeb CA, Arcangeli L, Block BA. 2003. Development of 11 microsatellite loci for population 557 studies in the swordfish, Xiphias gladius (Teleostei: Scombridae). Molecular Ecology Notes 558 3:147-149.

559 Reiss H, Hoarau G, Dickey-Collas M, Wolff WJ. 2009. Genetic population structure of marine 560 fish: mismatch between biological and fisheries management units. Fish and Fisheries 10:361561395.

562 Riccioni G, Ferrara G, Landi M, Sella M. 2010. Spatio-temporal genetic patterns in 563 Mediterranean bluefin tuna: population structuring and retention of genetic diversity. Collect. 564 Vol. Sci. Pap. ICCAT 65:996-1003.

565 Rooker JR, Secor DH, De Metrio G, Schloesser R, Block BA, Neilson JD. 2008. Natal homing 566 and connectivity in Atlantic bluefin tuna populations. Science 322:742-744.

567 Rosel PE, Block BA. 1996. Mitochondrial control region variability and global population 568 structure in the swordfish, Xiphias gladius. Marine Biology 125:11-22.

569 Ruggeri P, Splendiani A, Di Muri C, Fioravanti T, Santojanni A, Leonori I, De Felice A, 570 Biagiotti I, Carpi P, Arneri E. 2016a. Coupling demographic and genetic variability from 571 archived collections of European anchovy (Engraulis encrasicolus). PloS one 11:e0151507.

572 Ruggeri P, Splendiani A, Giovannotti M, Fioravanti T, Occhipinti G, Nisi Cerioni P, Caputo

573 Barucchi V. 2016b. The role of life-history traits, selective pressure and hydrographic boundaries 574 in shaping the genetic structure of the transparent goby, Aphia minuta. Marine Ecology 37:518575531.

576 Ruzzante DE, Mariani S, Bekkevold D, André C, Mosegaard H, Clausen LA, Dahlgren TG, 577 Hutchinson WF, Hatfield EM, Torstensen E. 2006. Biocomplexity in a highly migratory pelagic 578 marine fish, Atlantic herring. Proceedings of the Royal Society B: Biological Sciences 273:14595791464.

580 Smith BL, Lu C-P, García-Cortés B, Viñas J, Yeh S-Y, Bremer JRA. 2015. Multilocus Bayesian 581 estimates of intra-oceanic genetic differentiation, connectivity, and admixture in Atlantic 582 swordfish (Xiphias gladius L.). PloS one 10:e127979.

583 Tserpes G, Peristeraki P, Somarakis S. 2001. On the reproduction of swordfish (Xiphias gladius 584 L.) in the eastern Mediterranean. Col. Vol. Sci. Pap. ICCAT 52:740-744.

585 Tserpes G, Peristeraki P, Valavanis VD. 2008. Distribution of swordfish in the eastern 586 Mediterranean, in relation to environmental factors and the species biology. Hydrobiologia $587 \quad 612: 241$.

588 Tserpes G, Tsimenides N. 1995. Determination of age and growth of swordfish, Xiphias gladius 589 L., 1758, in the eastern Mediterranean using anal-fin spines. Fishery Bulletin 93:594-602.

590 Van Oosterhout C, Hutchinson WF, Wills DPM, Shipley P. 2003. Micro-Checker, version 2.2. 3.

591 Department of Biological Sciences and Department of Computer Science, University of Hull,

592 Hull, UK.

593 Van Wagner CE, Baker AJ. 1990. Association between mitochondrial DNA and morphological 594 evolution in Canada geese. Journal of Molecular Evolution 31:373-382. 
595 Viñas J, Bremer JA, Mejuto J, De La Serna JM, García-Cortés B, Pla C. 2007. Swordfish genetic 596 population structure in the North Atlantic and Mediterranean. Collect. Vol. Sci. Pap. ICCAT 597 61:99-106.

598 Viñas J, Pérez-Serra A, Vidal O, Alvarado Bremer JR, Pla C. 2010. Genetic differentiation

599 between eastern and western Mediterranean swordfish revealed by phylogeographic analysis of 600 the mitochondrial DNA control region. ICES Journal of Marine Science 67:1222-1229.

601 Waples RS, Gaggiotti O. 2006. INVITED REVIEW: What is a population? An empirical

602 evaluation of some genetic methods for identifying the number of gene pools and their degree of 603 connectivity. Molecular ecology 15:1419-1439.

604 Ward RD. 2000. Genetics in fisheries management. Hydrobiologia 420:191-201.

605 Ward RD, Woodwark M, Skibinski DOF. 1994. A comparison of genetic diversity levels in 606 marine, freshwater, and anadromous fishes. Journal of fish biology 44:213-232.

607 Weir BS, Cockerham CC. 1984. Estimating F-statistics for the analysis of population structure. 608 evolution 38:1358-1370.

609 Wenink PW, Baker AJ, Tilanus MG. 1993. Hypervariable-control-region sequences reveal 610 global population structuring in a long-distance migrant shorebird, the Dunlin (Calidris alpina).

611 Proceedings of the National Academy of Sciences 90:94-98.

612 Williams SM, Bennett MB, Pepperell JG, Morgan JA, Ovenden JR. 2016. Spatial genetic

613 subdivision among populations of the highly migratory black marlin Istiompax indica within the 614 central Indo-Pacific. Marine and Freshwater Research 67:1205-1214.

615 Zardoya R, Castilho R, Grande C, Favre-Krey L, Caetano S, Marcato S, Krey G, Patarnello T.

616 2004. Differential population structuring of two closely related fish species, the mackerel

617 (Scomber scombrus) and the chub mackerel (Scomber japonicus), in the Mediterranean Sea.

618 Molecular Ecology 13:1785-1798. 


\section{Table 1 (on next page)}

Sampling details for swordfish analysed in this study. 


\begin{tabular}{ccccc}
$\begin{array}{c}\text { Sampling area } \\
\text { (FAO fishing area/Geographical subarea) }\end{array}$ & $\begin{array}{c}\text { Sample } \\
\text { ID }\end{array}$ & Sampling date & $\mathrm{n}$ & $\begin{array}{c}\text { Size range } \\
\text { (LJFL) }\end{array}$ \\
\hline Balearic Sea (GSA 5, 6) & SPA & $07 / 16,08 / 16,09 / 16$ & 85 & $90-199 \mathrm{~cm}$ \\
& & $09 / 18$ & & \\
Southern Sicily (GSA 15, 16) & SIC & $07 / 16$ & & \\
& & $06 / 17,07 / 17$ & 61 & $83-236 \mathrm{~cm}$ \\
Aegean Sea (GSA 22) & & $06 / 18$ & & \\
Southern Adriatic Sea (GSA 18) & GRE & $08 / 16$ & 20 & $97-167 \mathrm{~cm}$ \\
Tyrrhenian Sea (GSA 10) & ADR & $09 / 16$ & 62 & $90-130 \mathrm{~cm}$ \\
Sardinian Sea (GSA 11.2) & TIR & $05 / 17$ & 16 & $90-170 \mathrm{~cm}$ \\
SAR & $06 / 17,10 / 17$ & 54 & $81-204 \mathrm{~cm}$ \\
Total & & $05 / 18,06 / 18$ & & \\
NW Atlantic (FAO Fishing area 21) & CAN & $08 / 18,09 / 18,10 / 18$ & 25 & $\mathrm{NA}$ \\
\hline
\end{tabular}

1 


\section{Table 2 (on next page)}

List of microsatellite loci used with corresponding repeat motif, fluorescent dye, annealing temperature, size ranges, and multiplex groups. 


\begin{tabular}{|c|c|c|c|c|c|}
\hline Locus & Repeat motif & $\begin{array}{l}\text { Fluorescent } \\
\text { dye }\end{array}$ & $\mathrm{T}_{\mathrm{a}}\left({ }^{\circ} \mathrm{C}\right)$ & $\begin{array}{l}\text { Size } \\
\text { range of } \\
\text { alleles }\end{array}$ & Multiplex \\
\hline Xgl-35 & $(\mathrm{CA})_{13}$ & NED & 58 & $196-251$ & 1 \\
\hline Xgl-121 & $(\mathrm{GT})_{6}(\mathrm{GC})_{5}(\mathrm{GT})_{6}$ & 6-FAM & 58 & $98-112$ & 1 \\
\hline$X g \mid-561$ & $(\mathrm{CA})_{6} \mathrm{GA}(\mathrm{CA})_{7}$ & VIC & 58 & 128154 & 1 \\
\hline Xgl-94 & $(G G A)_{8}$ & 6-FAM & 58 & 183-198 & 1 \\
\hline Xgl-106 & $(\mathrm{GA})_{10}$ & PET & 58 & 203-239 & 1 \\
\hline$X g \mid-65 b$ & $(\mathrm{CT})_{16}$ & 6-FAM & 58 & $261-297$ & 1 \\
\hline$X g \mid-74$ & $(A G G)_{7}$ & VIC & 58 & $232-250$ & 1 \\
\hline Xg-Sau98R1 & $(C A)_{8}$ & NED & 58 & $155-187$ & 2 \\
\hline Xgl-523b & $(\mathrm{GA})_{6} \mathrm{AAGG}(\mathrm{GA})_{6} \mathrm{GC}(\mathrm{GA})_{8}$ & 6-FAM & 58 & $95-99$ & 2 \\
\hline$X g \mid-14$ & $(\mathrm{CAT})_{6} \mathrm{CAC}(\mathrm{CAT})_{3} \mathrm{CAC}(\mathrm{CAT})_{4}(\mathrm{CGT})_{7}$ & 6-FAM & 58 & 143-186 & 2 \\
\hline Xg-148b & $(G G A)_{8}$ & 6-FAM & 58 & $221-236$ & 2 \\
\hline D2A & $(\mathrm{CCT})_{6}$ & NED & 50 & $289-298$ & 3 \\
\hline D2B & $(\mathrm{CAGT})_{8}$ & PET & 50 & 161-191 & 3 \\
\hline C8 & $(\mathrm{CTAT})_{22}$ & VIC & 50 & $143-247$ & 3 \\
\hline Xg-394 & $(\mathrm{TCC})_{9}$ & 6-FAM & 66 & $140-146$ & 4 \\
\hline $\mathrm{Xg}-402$ & $(\mathrm{TCC})_{5}+(\mathrm{CTT})_{2}$ & 6-FAM & 66 & 186-194 & 4 \\
\hline$X g-56$ & $(\mathrm{CA})_{16}$ & NED & 53 & $117-148$ & 5 \\
\hline Xg-66 & $(\mathrm{CA})_{11}$ & PET & 53 & $126-144$ & 5 \\
\hline Xg-144 & $(G G A)_{7}$ & PET & 53 & $152-170$ & 5 \\
\hline Xg-166 & $(\mathrm{CAA})_{7}$ & VIC & 53 & $121-142$ & 5 \\
\hline
\end{tabular}




\section{Table 3 (on next page)}

Descriptive statistics for 18 microsatellite loci over the seven swordfish locations.

$\mathrm{n}$, number of individuals typed; $N A$, allele number; MNA, mean number of alleles; AR, allelic richness; $\mathrm{H}_{0}$, observed heterozygosity; $\mathrm{H}_{\mathrm{e}}$, expected heterozygosity; $\mathrm{HW}$ disequilibrium , significance for the Hardy-Weinberg disequilibrium after Bonferroni correction; $F_{\text {is }}$, null allele frequencies; s.d. and s.e., standard deviation and standard error. 


\begin{tabular}{cccccccccc} 
Marker & $\mathrm{n}$ & $\mathrm{NA}$ & $\mathrm{MNA}(\mathrm{s} . \mathrm{d})$ & $\mathrm{AR}$ & $\mathrm{H}_{\mathrm{O}}(\mathrm{s} . \mathrm{d})$ & $\mathrm{H}_{\mathrm{E}}(\mathrm{s} . \mathrm{d})$ & $\begin{array}{c}H W \\
\text { disequilibrium }\end{array}$ & $\mathrm{F}_{\mathrm{IS}}(\mathrm{s} . \mathrm{e})$ & Null alleles (s.d) \\
\hline Xg|35 & 322 & 14 & $6.143(3.132)$ & 4.999 & $0.506(0.150)$ & $0.517(0.170)$ & n.s. & $0.002(0.023)$ & $0.008(0.020)$ \\
Xg|121 & 323 & 8 & $4.429(0.976)$ & 4.071 & $0.554(0.061)$ & $0.583(0.100)$ & n.s. & $0.043(0.039)$ & $0.024(0.036)$ \\
Xg|561 & 323 & 9 & $6.429(0.976)$ & 5.607 & $0.570(0.114)$ & $0.588(0.115)$ & n.s. & $-0.005(0.039)$ & $0.025(0.036)$ \\
Xg|94 & 321 & 6 & $5.143(0.378)$ & 4.927 & $0.587(0.113)$ & $0.740(0.015)$ & Significant & $0.250(0.053)$ & $0.086(0.058)$ \\
Xg|106 & 322 & 18 & $6.286(3.861)$ & 5.371 & $0.700(0.158)$ & $0.67(0.119)$ & n.s. & $0.000(0.042)$ & $0.012(0.016)$ \\
Xg|65b & 321 & 12 & $7.429(1.718)$ & 6.669 & $0.657(0.118)$ & $0.755(0.066)$ & Significant & $0.111(0.041)$ & $0.054(0.019)$ \\
Xg|Sau98R1 & 320 & 14 & $10.714(1.380)$ & 9.337 & $0.846(0.037)$ & $0.876(0.022)$ & n.s. & $0.034(0.027)$ & $0.013(0.014)$ \\
Xg|523 & 322 & 3 & $2.143(0.378)$ & 2.090 & $0.310(0.118)$ & $0.342(0.086)$ & n.s. & $0.095(0.084)$ & $0.245(0.112)$ \\
Xg|14 & 315 & 13 & $6.571(2.573)$ & 5.211 & $0.449(0.154)$ & $0.65(0.110)$ & Significant & $0.341(0.069)$ & $0.141(0.066)$ \\
Xg|148b & 323 & 4 & $3.143(0.378)$ & 2.967 & $0.341(0.081)$ & $0.343(0.062)$ & n.s. & $0.070(0.057)$ & $0.019(0.033)$ \\
D2A & 322 & 4 & $3.143(0.378)$ & 3.003 & $0.441(0.149)$ & $0.442(0.092)$ & n.s. & $0.040(0.035)$ & $0.105(0.053)$ \\
D2B & 322 & 7 & $3.857(1.464)$ & 3.352 & $0.580(0.103)$ & $0.624(0.044)$ & n.s. & $0.066(0.048)$ & $0.030(0.040)$ \\
C8 & 319 & 21 & $12.714(3.200)$ & 10.177 & $0.866(0.061)$ & $0.873(0.033)$ & n.s. & $0.002(0.027)$ & $0.011(0.025)$ \\
Xg|394 & 319 & 3 & $1.571(0.787)$ & 1.351 & $0.060(0.040)$ & $0.025(0.038)$ & n.s. & $-0.031(0.013)$ & $0.000(0.000)$ \\
Xg|402 & 321 & 2 & $1.429(0.535)$ & 1.320 & $0.047(0.021)$ & $0.020(0.026)$ & n.s. & $-0.017(0.009)$ & $0.000(0.000)$ \\
Xg56 & 314 & 13 & $8.571(2.225)$ & 8.150 & $0.780(0.039)$ & $0.795(0.050)$ & n.s. & $0.008(0.026)$ & $0.020(0.032)$ \\
Xg144 & 317 & 7 & $4.000(1.000)$ & 3.494 & $0.596(0.072)$ & $0.674(0.025)$ & Significant & $0.082(0.047)$ & $0.049(0.033)$ \\
Xg166 & 308 & 8 & $6.429(0.787)$ & 6.319 & $0.637(0.141)$ & $0.740(0.031)$ & Significant & $0.108(0.065)$ & $0.121(0.066)$ \\
\hline
\end{tabular}




\section{Table 4(on next page)}

Descriptive statistics for each location over all loci.

$\mathrm{n}$, sample size; MNA, mean number of alleles; $A R$, allelic richness; $H_{0}$, observed heterozygosity; $\mathrm{H}_{\mathrm{e}}$, expected heterozygosity; $\mathrm{HW}$ disequilibrium, significance for the Hardy-Weinberg disequilibrium after Bonferroni correction; $F_{i s}$, mean null allele frequencies; s.d. and s.e., standard deviation and standard error. 


\begin{tabular}{ccccccccc} 
Location & $n$ & MNA (s.d) & AR & $H_{O}(s . d)$ & $H_{E}($ s.d $)$ & $\begin{array}{c}\text { HW } \\
\text { disequilibrium }\end{array}$ & $F_{I S}($ s.e $)$ & Null alleles (s.d) \\
\hline ADR & 62 & $5.556(3.166)$ & 4.569 & $0.543(0.253)$ & $0.560(0.254)$ & n.s. & $0.027(0.077)$ & $0.043(0.058)$ \\
SIC & 61 & $5.444(3.072)$ & 4.474 & $0.505(0.247)$ & $0.558(0.242)$ & Significant & $0.086(0.169)$ & $0.058(0.096)$ \\
GRE & 20 & $4.875(1.928)$ & 4.278 & $0.552(0.120)$ & $0.609(0.120)$ & n.s. & $0.096(0.124)$ & $0.049(0.062)$ \\
SPA & 85 & $6.062(3.492)$ & 4.453 & $0.571(0.180)$ & $0.621(0.175)$ & Significant & $0.077(0.138)$ & $0.059(0.058)$ \\
TIR & 16 & $4.706(2.114)$ & 4.443 & $0.554(0.223)$ & $0.583(0.205)$ & n.s. & $0.037(0.217)$ & $0.042(0.056)$ \\
SAR & 54 & $5.706(3.016)$ & 4.495 & $0.503(0.229)$ & $0.574(0.219)$ & Significant & $0.126(0.156)$ & $0.073(0.091)$ \\
CAN & 25 & $8.938(4.389)$ & 7.048 & $0.715(0.119)$ & $0.770(0.153)$ & Significant & $0.059(0.109)$ & $0.078(0.104)$ \\
\hline
\end{tabular}

1 
Figure 1

sampling map

Map of the Mediterranean Sea and Northwestern Atlantic with locations of the Swordfish samples collected for the present study (dots). The approximate extents of the spawning areas are shown in light grey (Arocha et al., 2007).

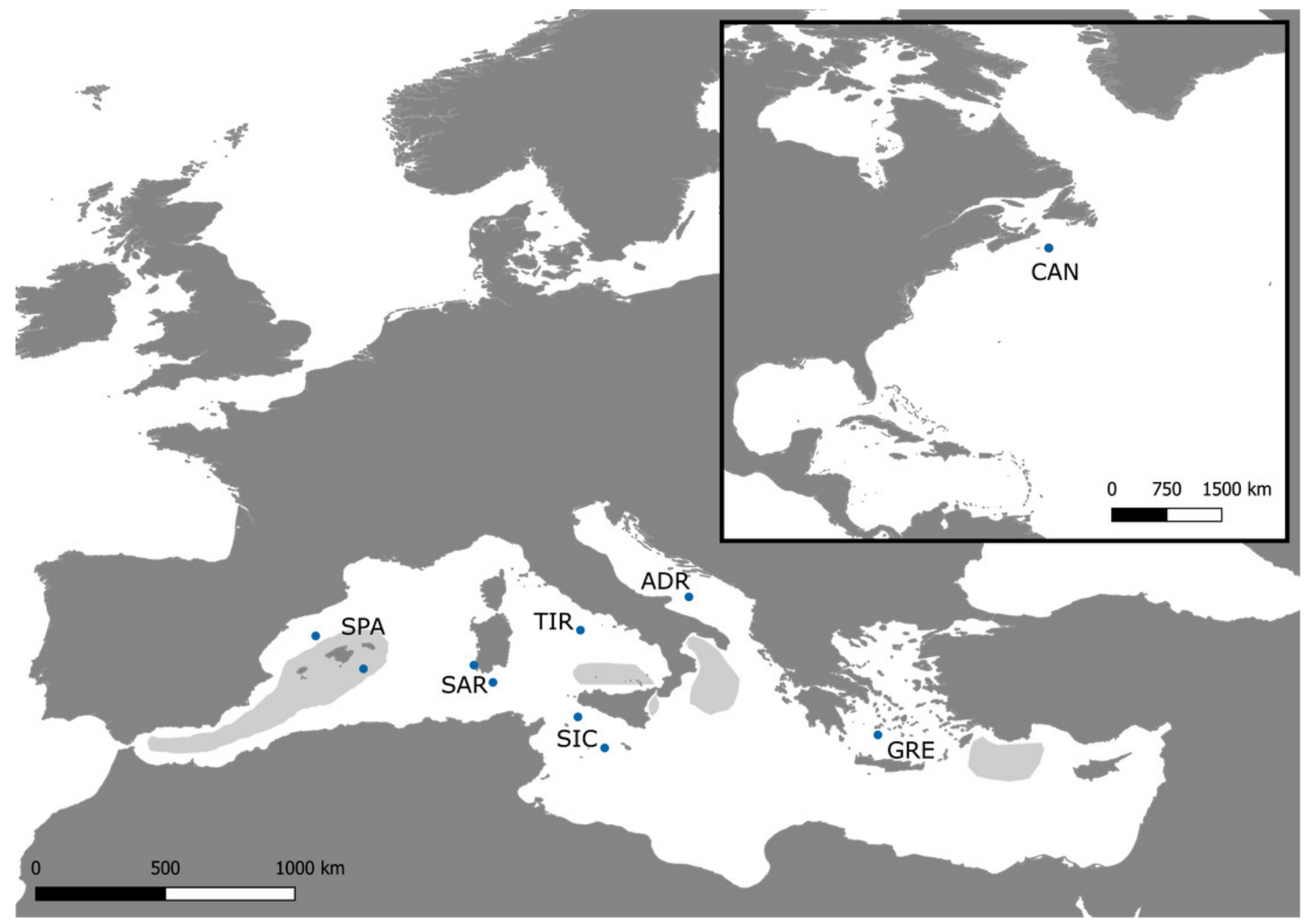




\section{Figure 2}

Bayesian structure analysis implemented in STRUCTURE

(A) Plot of Delta K and (B) Mean $\operatorname{LnP}(K)$ according to $K$. (C) Structure clustering results obtained at $K=2$. Barplots showing posterior probabilities of swordfish individual genotypes (as bars) assigned to each population. The black lines separate sampling localities.
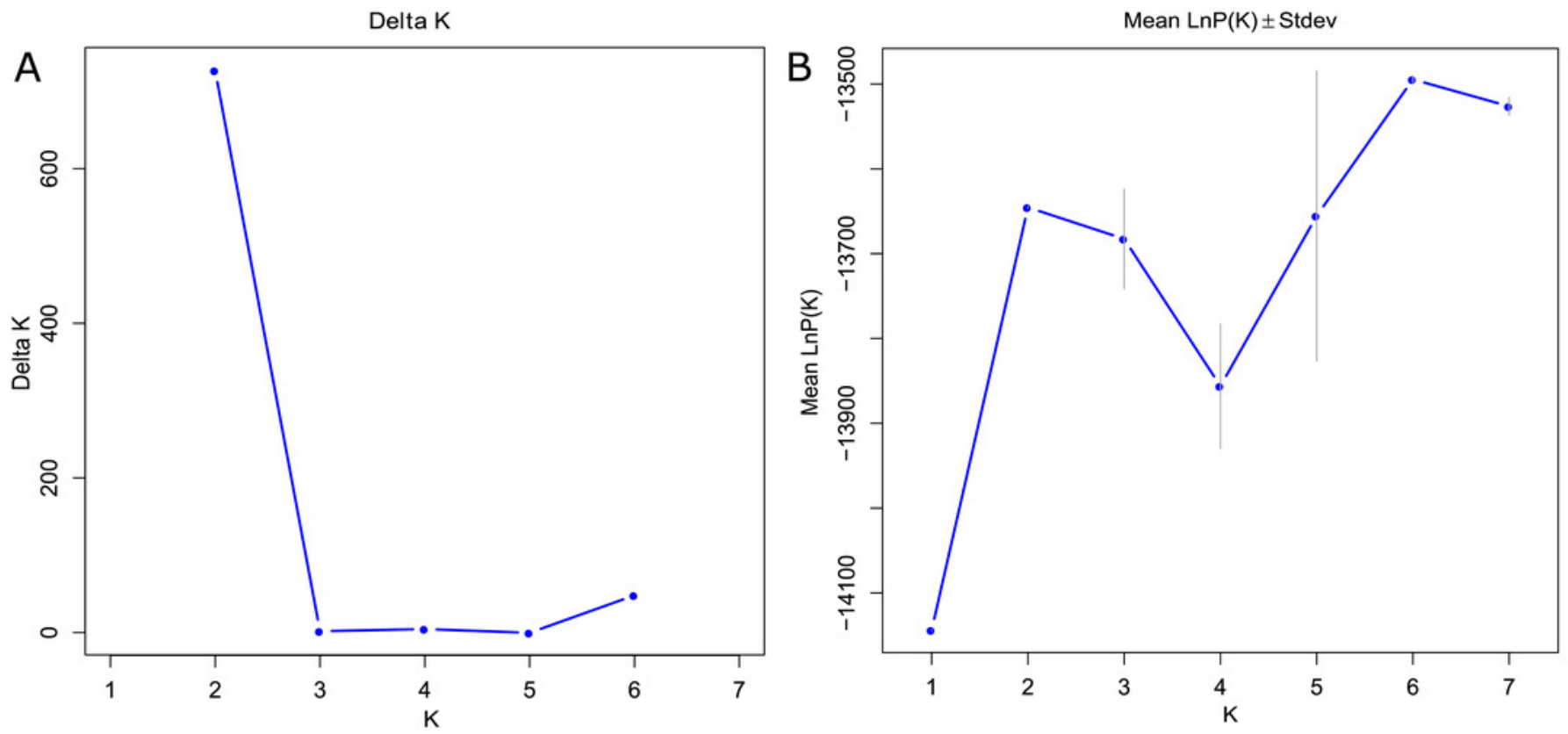

C $A D R$ SIC GRE SPA TIR SAR CAN 


\section{Figure 3}

Discriminant analysis of principal components (DAPC) with a priori geographical information.

Figure 3 Scatterplot of the discriminant analysis of principal components of the microsatellite data for 7 locations. Individual genotypes appear as dots. Each population is indicated by abbreviation reported in table 1 .

$\circ$ ADR ○ SIC ○ GRE ○ SPA ○ TIR ○ SAR ○ CAN

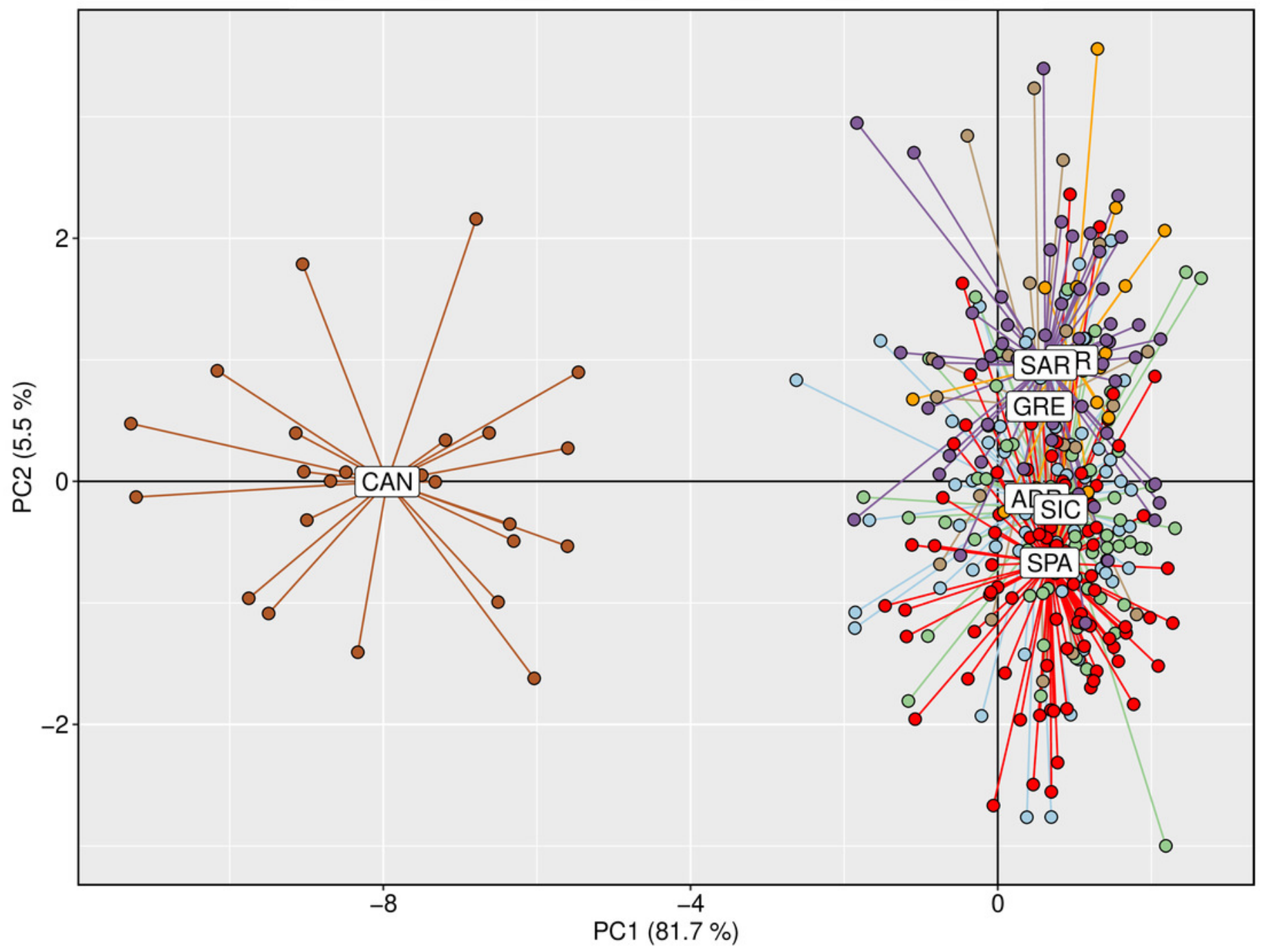




\section{Figure 4}

Discriminant analysis of principal components (DAPC) results including Canadian sample

(A) The optimal number of clusters (K) as determined by 'k-means'. (B-E) Scatterplots based on the DAPC output for $\mathrm{K}$ from 2 to 5 . Dots represent different individuals and colours represent different clusters. (F) Barplots showing the probabilities of assignment of individuals to $\mathrm{K}$ from 2 to 5 genetic DAPC clusters. Each individual is represented as a vertical bar, with colours corresponding to probabilities of membership into the clusters.
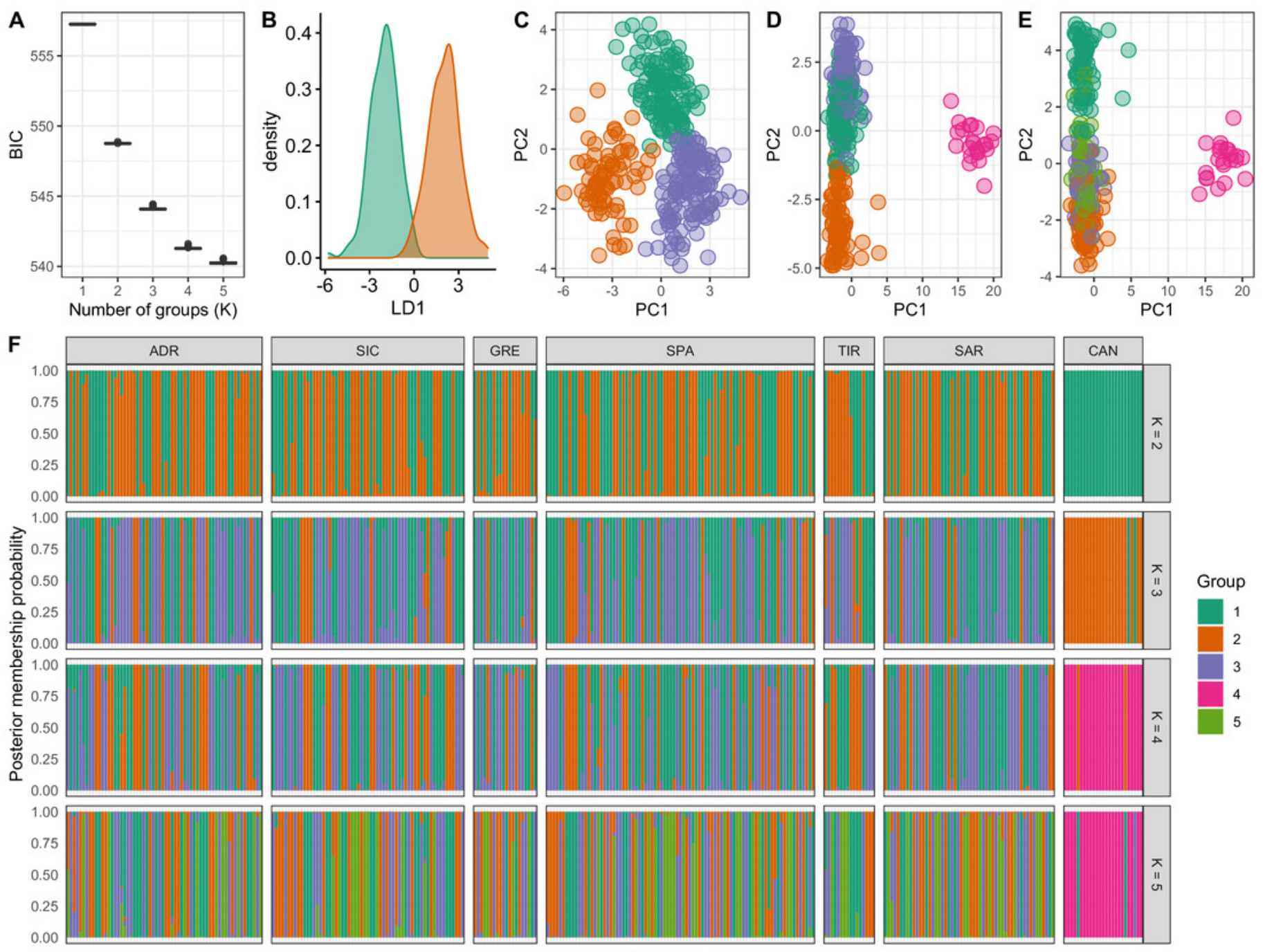

Individuals 


\section{Figure 5}

Discriminant analysis of principal components (DAPC) results excluding the Canadian sample

(A) The optimal number of clusters (K) as determined by 'k-means'. (B-D) Scatterplots based on the DAPC output for $\mathrm{K}$ from 2 to 4 . Dots represent different individuals and colours represent different clusters. (E) Barplots showing the probabilities of assignment of individuals to $\mathrm{K}$ from 2 to 4 genetic DAPC clusters. Each individual is represented as a vertical bar, with colours corresponding to probabilities of membership into the clusters.
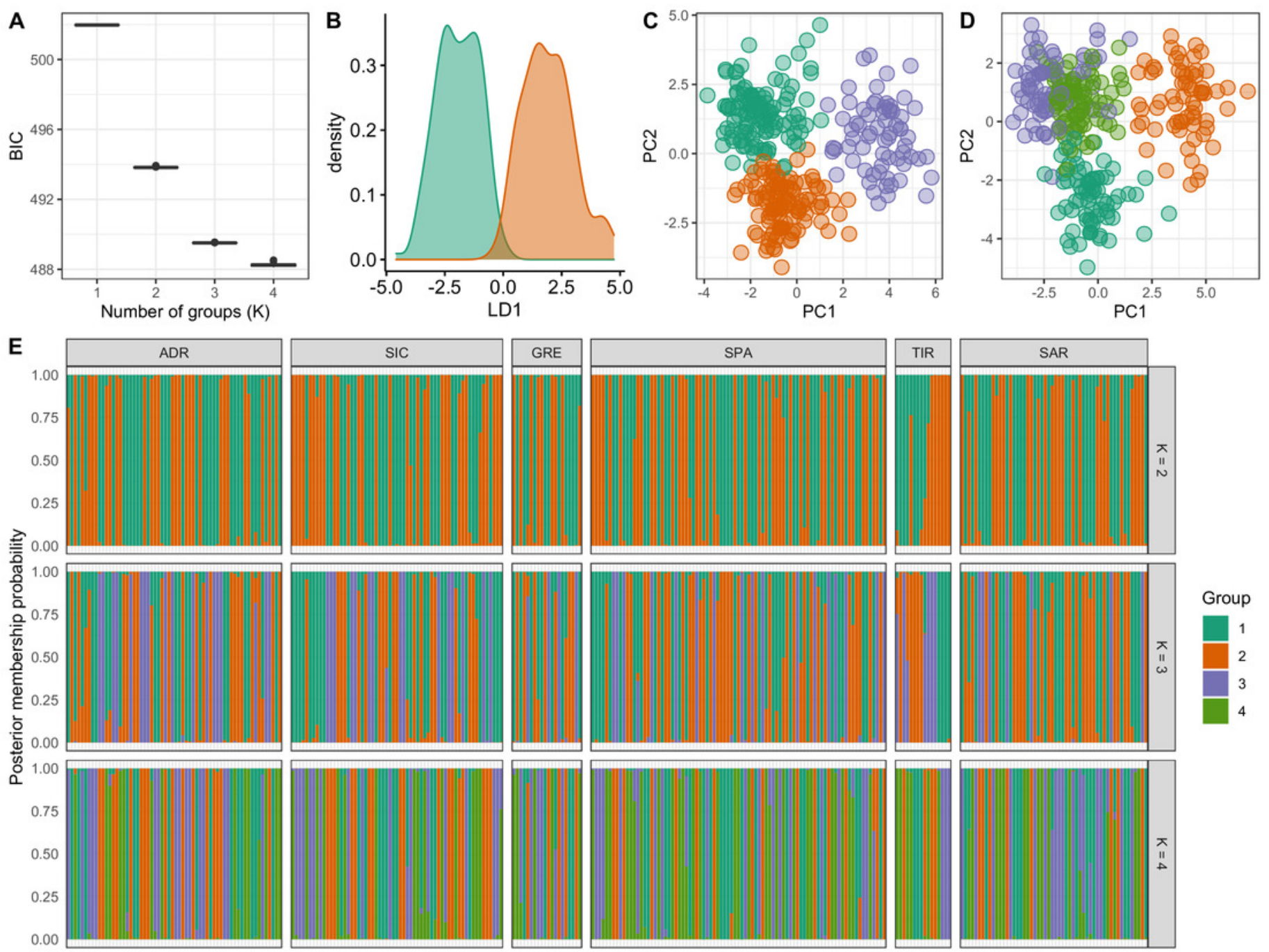